\title{
Procedimentos de tradução em HQs digitais envolvendo a cultura pop
}

\section{Translation procedures in digital comics dealing with pop culture}

\author{
Glauber Lopes da Nóbrega*
}

Resumo: Este artigo tem como objeto a tradução de webcomics, tiras em quadrinhos digitais que lidam com o texto das HQs, sob o viés da cultura pop. 0 arcabouço teórico envolve os procedimentos de tradução propostos por Vinay e Darbelnet em 1958 e revisados por Barbosa em 1990. Além disso, foram utilizados exemplos de elementos da cultura pop para ilustrar cada procedimento apresentado. Houve, posteriormente, a análise de tiras que foram traduzidas conforme tais procedimentos.

Palavras-chave: Webcomics; procedimentos de tradução; cultura pop.

Abstract: The object of this article is the translation of webcomics, digital comic strips that deal with the text of comics related to pop culture aesthetics. The theoretical framework includes translation procedures proposed by Vinay and Darbelnet in 1958 and uptaded by Barbosa in 1990. Besides, elements of pop culture were used to exemplify each procedure that was presented. Afterwards, some comic strips translated according to such procedures were analyzed.

Keywords: Webcomics; translation procedures; pop culture.

\footnotetext{
* Mestre em Estudos da Tradução pelo POSTRAD (Pós-graduação em Estudos da Tradução / UnB-DF)
} 
NóBREGA, G. L. DA - Procedimentos de tradução em HQs digitais envolvendo cultura pop

\section{Procedimentos de tradução}

O corpus deste artigo é a webcomic (tira em quadrinhos digital) Player

vs Player (PVP), disponibilizada online $\mathrm{e}$ diariamente no websitewww.pvponline.com desde maio de 1998. Scott R. Kurtz, seu criador, inicialmente visou o público consumidor de consoles e jogos de videogame, porém, progressivamente, passou a tratar sobre todo e qualquer tópico que envolve a cultura pop.

A escolha das tiras foi inicialmente feita entre aquelas do acervo digital da webcomic PvP que se encaixassem no conceito de que o humor apresentado faria referência direta a elementos de cultura pop, sejam eles as próprias HQs, filmes de cinema ou séries de TV. Todas as tiras foram por mim traduzidas, tendo como referencial teórico o conceito de procedimentos de tradução, sendo que acrescentei elementos do universo da cultura pop para exemplificar cada um deles.

O trabalho pioneiro a respeito dos procedimentos de tradução foi desenvolvido por Vinay e Darbelnet (1958). Neste trabalho, utiliza-se a proposta de Barbosa (1990), que utiliza uma recategorização dos procedimentos originais, apresentando treze deles: a tradução palavra por palavra, a tradução literal, a transposição, a modulação, a equivalência, a omissão vs. a explicitação, a compensação, a reconstrução de períodos, as melhorias, a transferência - que engloba o estrangeirismo, a transliteração, a aclimatação e a transferência com explicação - a explicação, o decalque e a adaptação.

A tradução palavra por palavra é descrita por Barbosa (1990: 64) segundo a definição de Aubert (1987: 15), como "aquela em que determinado segmento textual (palavra, frase, oração) é expresso na língua da tradução mantendo-se as mesmas categorias numa mesma ordem sintática, utilizando vocábulos cujo semanticismo seja (aproximativamente) idêntico ao dos vocábulos correspondentes 
NóBREGA, G. L. DA - Procedimentos de tradução em HQs digitais envolvendo cultura pop

no texto na língua original”. A HQ Captain America: Sentinel of Liberty, vertida como Capitão América: Sentinela da Liberdade, apresenta tal procedimento.

Barbosa (1990: 65) define tradução literal, novamente segundo Aubert (1987), como "aquela em que se mantém uma fidelidade semântica estrita, adequando, porém, a morfossintaxe às normas gramaticais da língua da tradução”. Pode-se citar a tradução original, feita pela Editora Brasil América (EBAL) no Brasil, para os membros do grupo Legião de Super-Heróis, da editora americana DC Comics: Lightning Lad tornou-se Rapaz Relâmpago; Phantom Girl, Moça Fantasma; Element Lad (Rapaz Elemento) e Light Lass, Moça de Luz (tradução inadequada para uma heroína com o poder de tornar tudo mais leve. Ou seja, houve confusão sobre o significado de "light".

A transposição, segundo Barbosa (1990: 28), "consiste em um afastamento, no plano sintático, da forma do texto na língua original. Assim, um significado que era expresso no texto na língua original por um significante de uma determinada categoria gramatical (parte do discurso), passa a ser expresso, no texto na língua da tradução, por um significante de outra categoria gramatical, sem que, com isso, fique alterado o conteúdo, ou a mensagem, do texto na língua original. Isto ocorre com uma das definições para o personagem Batman. Em inglês, temos The Dark Knight, que é traduzido como $O$ Cavaleiro das Trevas. Temos aí um adjetivo (Dark) substituído por uma preposição seguida de um substantivo (das Trevas), mantendo a mesma ideia do original.

Segundo Barbosa (1990: 67), a modulação "consiste em reproduzir a mensagem do texto na língua original na tradução sob um ponto de vista diverso, refletindo uma diferença na maneira como as línguas interpretam a experiência do real". A equipe canadense da editora Marvel Comics, Alpha Flight, dificilmente poderia ser chamada de Voo Alfa (embora o termo tenha sido utilizado na tradução de sua participação no desenho dos $X$-Men na década de 90). É muito mais apropriada a solução encontrada pela Editora Abril na década de 80: Tropa Alfa. 
NóBREGA, G. L. DA - Procedimentos de tradução em HQs digitais envolvendo cultura pop

Barbosa (1990: 67) indica que a equivalência "consiste em substituir um segmento da língua original por outro segmento da língua da tradução que não o traduz literalmente, mas the é funcionalmente equivalente". É o caso de onomatopeias como smack!, que se torna chuac! ou sob!, que é traduzido como sniff! ou chuif!

Barbosa (1990: 68) utiliza as definições de omissão e explicitação de Vázquez-Ayora (1977: 46). A omissão "consiste em omitir elementos do texto na língua original que, do ponto da vista da língua da tradução, são desnecessários ou excessivamente repetitivos". É usada na tradução do inglês para o português em relação aos pronomes pessoais, muitas vezes dispensáveis no português devido às desinências verbais que deixam clara a pessoa do verbo. Assim, evita-se uma repetição excessiva prejudicial no texto traduzido. É o caso do lema do personagem Wolverine, membro do grupo $X$ Men, da Marvel Comics: "I'm the best there is at what I do", que foi traduzido como "Sou o melhor naquilo que faço" "Na tradução do português para o inglês seria usado, para o mesmo caso, o procedimento inverso, a explicitação do pronome, pois sua presença é obrigatória em inglês" (BARBOSA 1990: 68).

A compensação (BARBOSA: 69) "consiste em deslocar um recurso estilístico, ou seja, quando não é possível reproduzir no mesmo ponto, no texto na língua da tradução, um recurso estilístico usado no texto na língua original, o tradutor pode usá-lo, com efeito equivalente, em outro ponto do texto". Tal procedimento ocorre na versão em português do juramento da Tropa dos Lanternas Negros, personagens da DC Comics: o original "The Blackest Night falls from the skies, the darkness grows as all light dies. We crave your hearts and your demise, by my black hand, the dead shall rise!" tornou-se "No alto dos céus a Noite mais Densa desponta, enquanto a luz morre a escuridão toma conta, almejamos seu fim e miramos seu coração. Pela minha mão negra os mortos se erguerão!". 
NóBREGA, G. L. DA - Procedimentos de tradução em HQs digitais envolvendo cultura pop

A reconstrução de períodos é descrita por Newmark (1981: 55) como um procedimento que "consiste em redividir ou reagrupar os períodos e orações do original ao passá-los para a língua da tradução". Segundo Barbosa (1990: 70), na tradução do português para o inglês é muitas vezes necessário distribuir as orações complexas do português em períodos mais curtos em inglês. Na tradução do inglês para o português ocorre o inverso. No original, o juramento da Tropa dos Lanternas Verdes, personagens da DC Comics é: "In brightest day, in blackest night, no evil shall escape my sight. Let those who worship evil's might, beware my power - green lantern's light!". Na versão brasileira, temos: "No dia mais claro, na noite mais densa, o mal sucumbirá ante minha presença. Todo aquele que venera o mal há de penar, quando o poder do Lanterna Verde enfrentar!".

Barbosa (1990: 70) usa a descrição de Newmark (1981: 55) para o procedimento de melhorias, que "consiste em não se repetirem na tradução os erros de fato ou outros tipos de erro cometidos no texto na língua original". Alguns gramáticos ainda consideram o lema do seriado Jornada nas Estrelas (1967-1969): “To boldly go where no man has gone before" gramaticalmente incorreto, por incluir um advérbio (boldly) entre a preposição (to) e o verbo (go). Na verdade, tal estrutura, chamada de "split infinitive", se configura mais como uma falha estilística do que um erro gramatical, propriamente. Tal problema inexiste na versão brasileira “Audaciosamente indo onde nenhum homem jamais esteve". Entretanto, a tradução, mesmo considerada clássica e repetida à exaustão por fãs brasileiros da série, não soa muito natural em português. Uma solução mais adequada seria "Ir sem medo" em vez de "Audaciosamene indo", incluindo infinitivo e locução adverbial, recursos mais normais em português.

A transferência "consiste em introduzir material textual da língua original no texto na língua da tradução". Pode assumir quatro formas. A primeira é o estrangeirismo, que "consiste em transferir (transferir ou copiar) para o texto na língua da tradução vocábulos ou expressões da língua original que se refiram a um conceito, técnica ou objeto mencionado no texto na 
NóBREGA, G. L. DA - Procedimentos de tradução em HQs digitais envolvendo cultura pop

língua original que seja desconhecido para os falantes da língua da tradução" (BARBOSA 1990: 71). “O vocábulo ou expressão aparecerá no texto na língua da tradução entre aspas, em itálico ou sublinhado marcando o itálico" (BARBOSA 1990: 72). É o que acontece em relação aos nomes de personagens de HQs que são mantidos no original, como Batman, Robin, Superman e Flash, da DC Comics e Gambit e Wolverine, da Marvel Comics. A segunda é o estrangeirismo transliterado (transliteração), "que consiste em substituir uma convenção gráfica por outra. Como procedimento de tradução, ocorre em casos de extrema divergência entre duas línguas" (BARBOSA 1990: 73). É o que ocorre na capa da edição brasileira do mangá (histórias em quadrinhos japonesas) do personagem Rurouni Kenshin (Kenshin, o Andarilho - também conhecido no Brasil como Samurai $X$ ).

Figura 1 - Comparação entre a capa original e a brasileira do último volume de Rurouni Kenshin. ${ }^{1}$

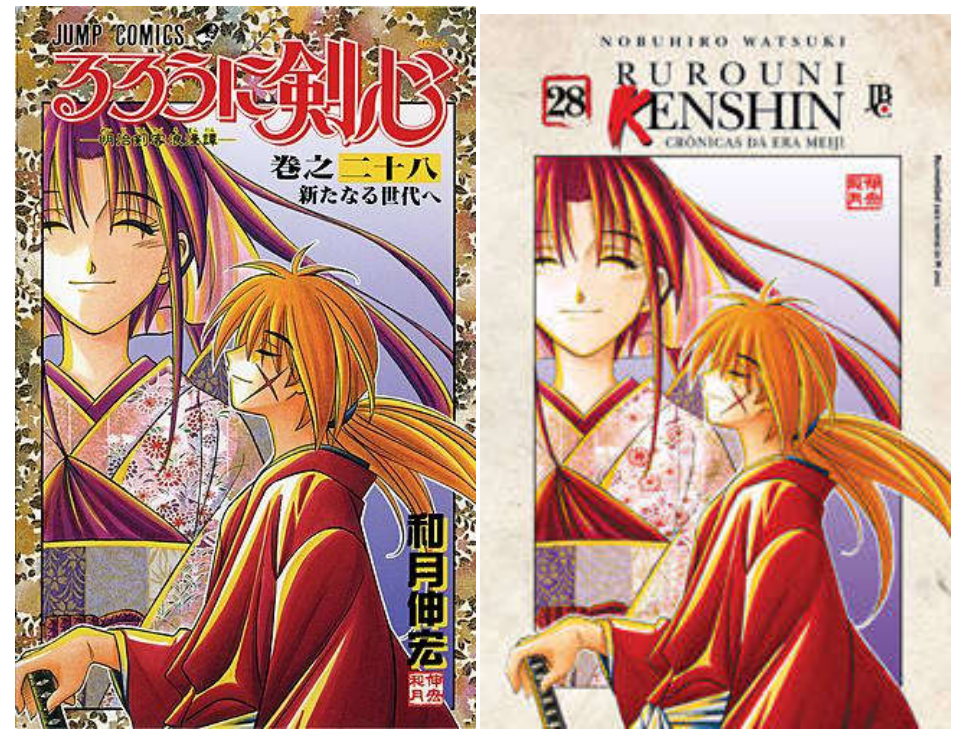

A terceira forma é o estrangeirismo aclimatado (aclimatação), "processo pelo qual os empréstimos são adaptados à língua que os toma"

\footnotetext{
1 Figura 1 disponível em: https://en.wikipedia.org/wiki/Rurouni_Kenshin e
} http://mangasjbc.uol.com.br/rurouni-kenshin-28. 
NóBREGA, G. L. DA - Procedimentos de tradução em HQs digitais envolvendo cultura pop

(BARBOSA 1990: 73). É o que acontece em relação à personagem Nocaute (Knockout) da DC Comics e Rocky Racum (Rocket Racoon), da Marvel Comics. A quarta modalidade é a transferência com explicação. Barbosa (1990: 72) explica que

a condição necessária para o emprego da transferência na tradução é que o leitor possa apreender seu significado através do contexto. Muitas vezes o texto na língua original não permite esta compreensão, sendo necessário acrescentar ao texto na língua da tradução procedimentos adicionais à transferência para proporcionar ao leitor um entendimento do significado do mesmo.

É o que ocorre com o estado fictício americano onde se localiza a cidade de Patópolis, na qual residem personagens do universo Disney, tais quais o Pato Donald, seus sobrinhos Huguinho, Zezinho e Luizinho e o Tio Patinhas, chamado de Calisota. Por vezes, na versão nacional, é incluída a nota explicativa "estado localizado entre a Califórnia e Minnesota".

A explicação ocorre quando "havendo a necessidade de eliminar do texto na língua da tradução os estrangeirismos para facilitar a compreensão, pode-se substituir o estrangeirismo pela sua explicação". É o que ocorre na versão brasileira da série Twilight Zone (1959-1964). Ao invés de se nomear a dimensão fictícia homônima onde se passam as histórias fantásticas apresentadas no seriado, preferiu-se explicar a natureza das mesmas (Além da Imaginação). Este é o monólogo original apresentado no início de cada episódio: "There is a fifth dimension beyond that which is known to man. It is a dimension as vast as space and as timeless as infinity. It is the middle ground between light and shadow, between science and superstition, and it lies between the pit of man's fears and the summit of his knowledge. This is the dimension of imagination. It is an area which we call the Twilight Zone". Já em português, ficou assim: "Há uma quinta dimensão além daquelas conhecidas pelo Homem. É uma dimensão tão vasta quanto o espaço e tão desprovida de tempo quanto o infinito. É o espaço intermediário entre a luz e a sombra, entre a ciência e a superstição; e se encontra entre o abismo dos 
NóBREGA, G. L. DA - Procedimentos de tradução em HQs digitais envolvendo cultura pop

temores do Homem e o cume dos seus conhecimentos. É a dimensão da fantasia. Uma região Além da Imaginação".

O decalque, segundo Barbosa (1990: 76), “consiste em traduzir literalmente sintagmas ou tipos frasais da língua original do texto na língua da tradução", como na HQ Justice League Task Force, que tornou-se Força Tarefa Liga da Justiça.

A adaptação é para Barbosa (1990: 76) o limite extremo da tradução: "aplica-se em casos onde a situação toda a que se refere o texto na língua original não existe na realidade extralinguística dos falantes da língua da tradução". Um exemplo é um dos inimigos do herói Demolidor (Daredevil), da Marvel Comics, chamado Bullseye. Tal termo indica o círculo central de um alvo. Um equivalente seria a expressão "Na Mosca", que não garantiria um bom nome para o personagem, que é conhecido como Mercenário (genérico, porém adequado). 
NóBREGA, G. L. DA - Procedimentos de tradução em HQs digitais envolvendo cultura pop

\section{Análise das webcomics}

REPRESENT

07/03/13
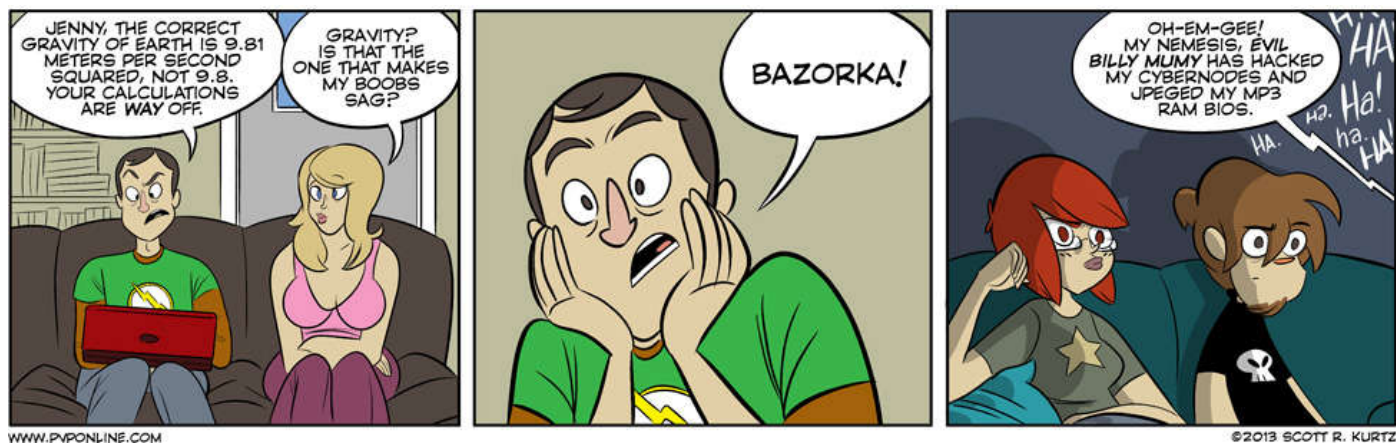

\section{ME REPRESENTA}

03/07/13
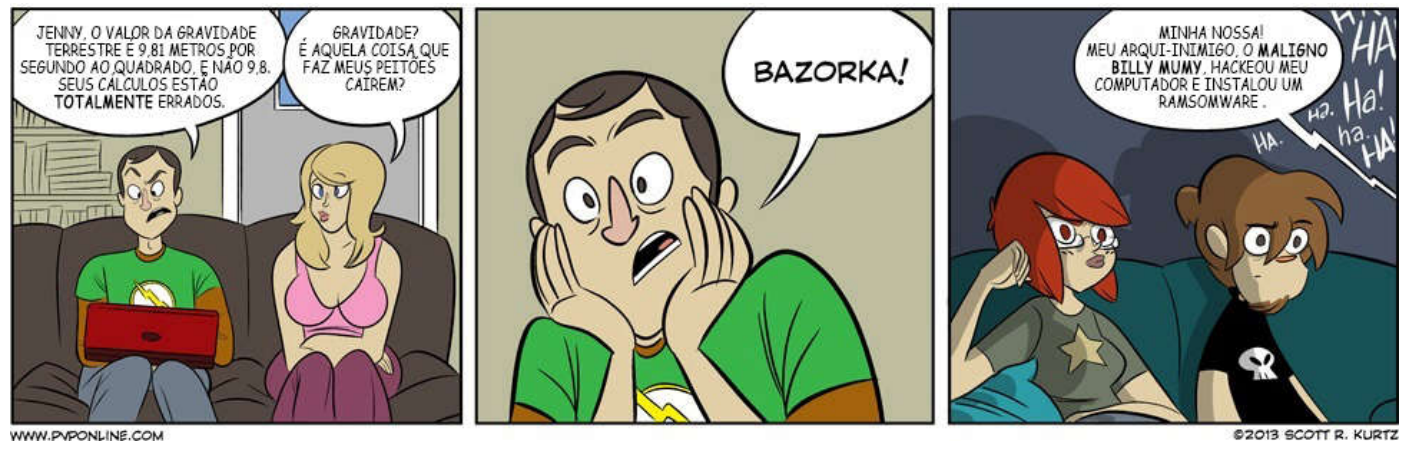

O estrangeirismo ocorre em dois momentos. O termo bazorka é o equivalente ao bordão do personagem Sheldon Cooper: Bazinga!, uma expressão usada pelo personagem quando ele decide fazer piadas ou comentários sarcásticos. Nenhuma das palavras tem algum significado, sendo termos inventados pelo personagem de The Big Bang Theory e seu correspondente na tira acima. Ransomware é outro termo que vem sendo utilizado em sua forma original para avisar os usuários de computadores sobre o cuidado quanto ao recebimento de arquivos ou acesso a websites de procedência duvidosa. A transposição foi utilizada no título da tira, com o acréscimo do pronome "me", que forma a expressão utilizada há algum tempo nas redes sociais brasileiras para mostrar, por exemplo, a indignação quanto a 
NóBREGA, G. L. DA - Procedimentos de tradução em HQs digitais envolvendo cultura pop

alguns políticos ("Fulano de Tal não me representa"). Como o seriado The Big Bang Theory é considerado um dos melhores retratos sobre nerds e geeks apresentados na televisão, considerei tal solução adequada.

\section{TALES TO ASTONISH}

\section{$07 / 20 / 2015$}
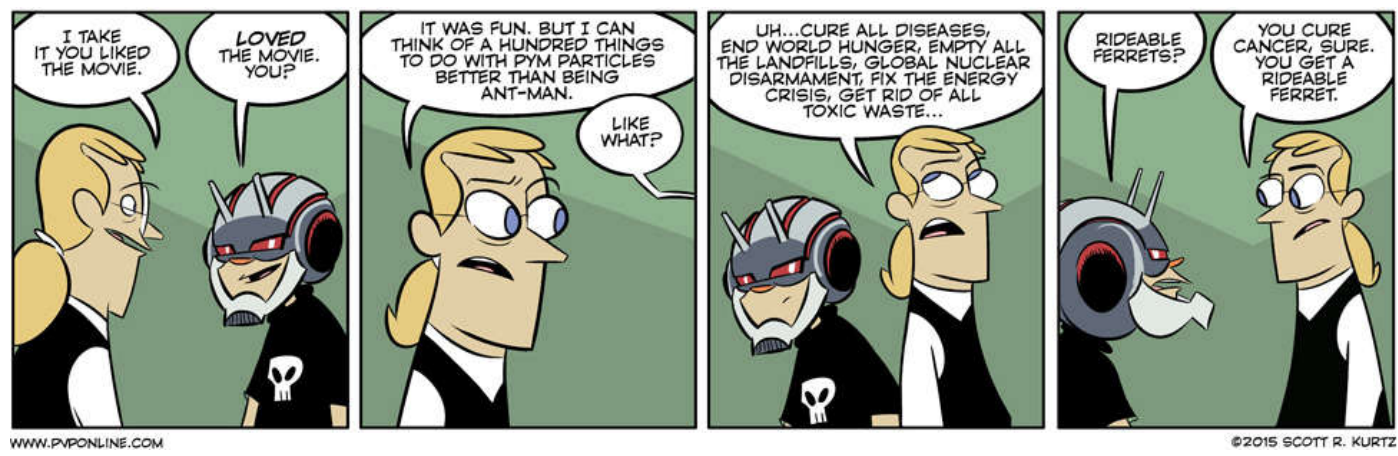

EU SOU A TRIÔNICA...

$20 / 07 / 2015$
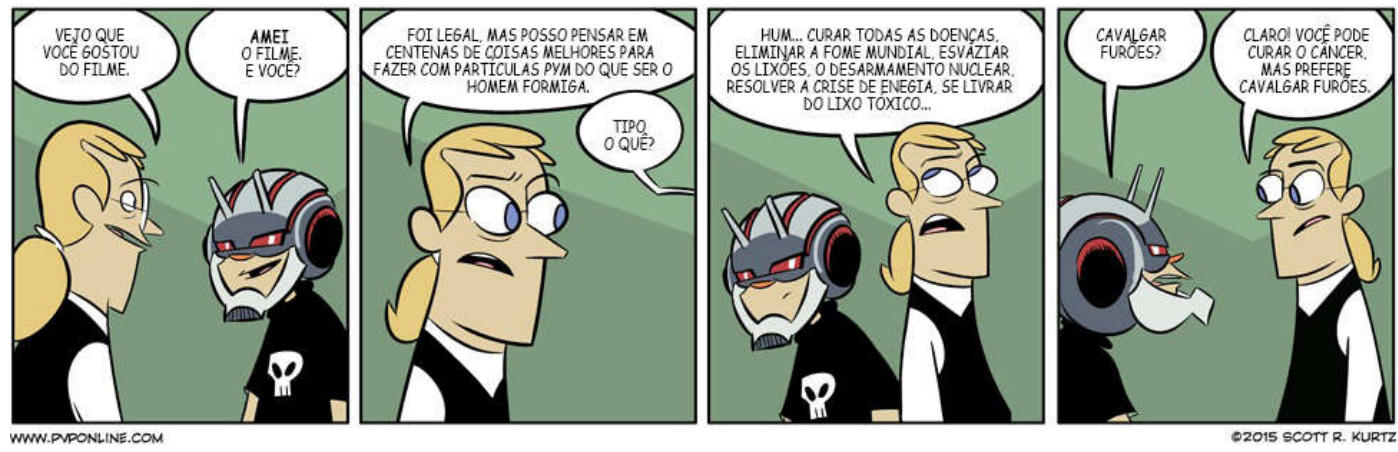

Utilizei a adaptação como procedimento de tradução do título da tira. "Tales to Astonish" era o nome da HQ na qual o personagem Homem-Formiga fez sua primeira aparição, no número 27 da publicação, no ano de 1959 . 0 problema que há em relação a sua tradução é que os títulos da Marvel Comics da época, onde novos personagens eram introduzidos antes de ganharem seus títulos próprios, tais quais Tales of Suspense (Homem de Ferro) e Journey into Mistery (Thor), não tiveram versão nacional. Resolvi, então, fazer menção a outro herói, este um inseto verdadeiro, a Formiga Atômica, em cujo desenho 
NóBREGA, G. L. DA - Procedimentos de tradução em HQs digitais envolvendo cultura pop

animado (1965) sempre gritava ao se transformar: “Eu sou a triônica, Formiga Atômica".

MOM SOLO

$09 / 23 / 2014$
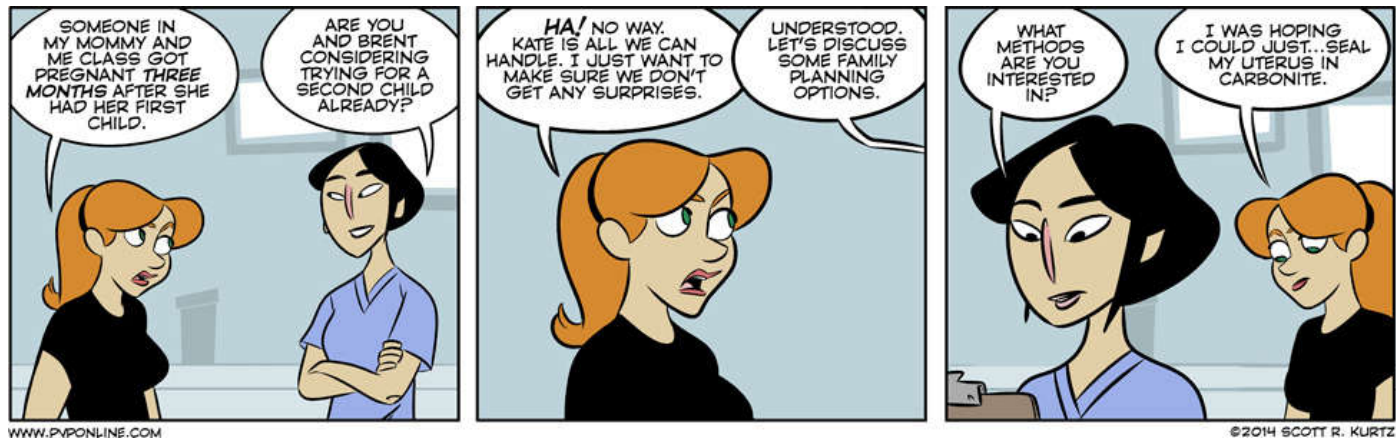

MÃE SOLO

$23 / 09 / 2014$
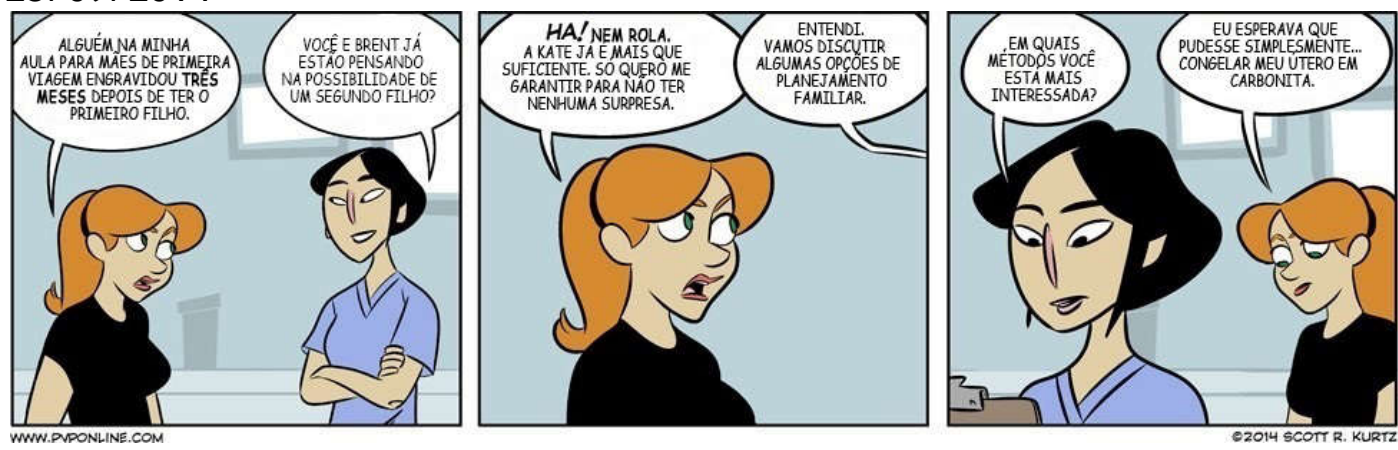

0 procedimento de modulação é verificado no trecho "sealed in carbonite". Além da possível tradução "selado em carbonita" parecer estranho em português, a cena do filme no qual o personagem Han Solo é capturado e colocado em êxtase na substância citada o mostra sendo imerso e resfriado nela. Além disso, a expressão “congelado em carbonita” é conhecida pelos fãs da saga Star Wars, um conhecimento intertextual necessário para o tradutor que deseja lidar com tal material. 
NóBREGA, G. L. DA - Procedimentos de tradução em HQs digitais envolvendo cultura pop

ROAR, RINSE, REPEAT

$05 / 12 / 2014$
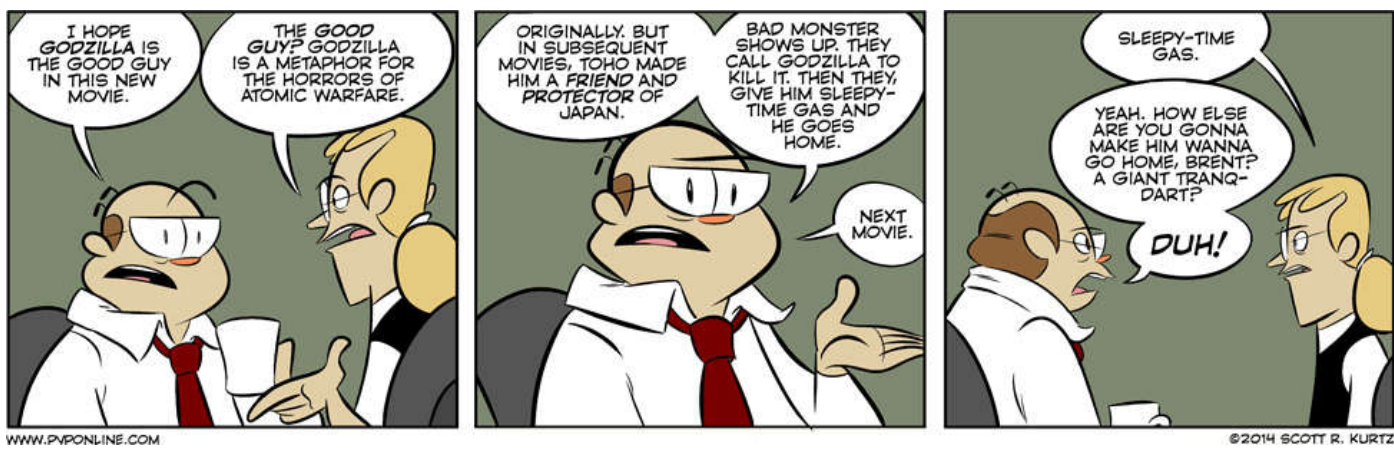

RUGIR, REPOUSAR, REPETIR

$12 / 05 / 2014$
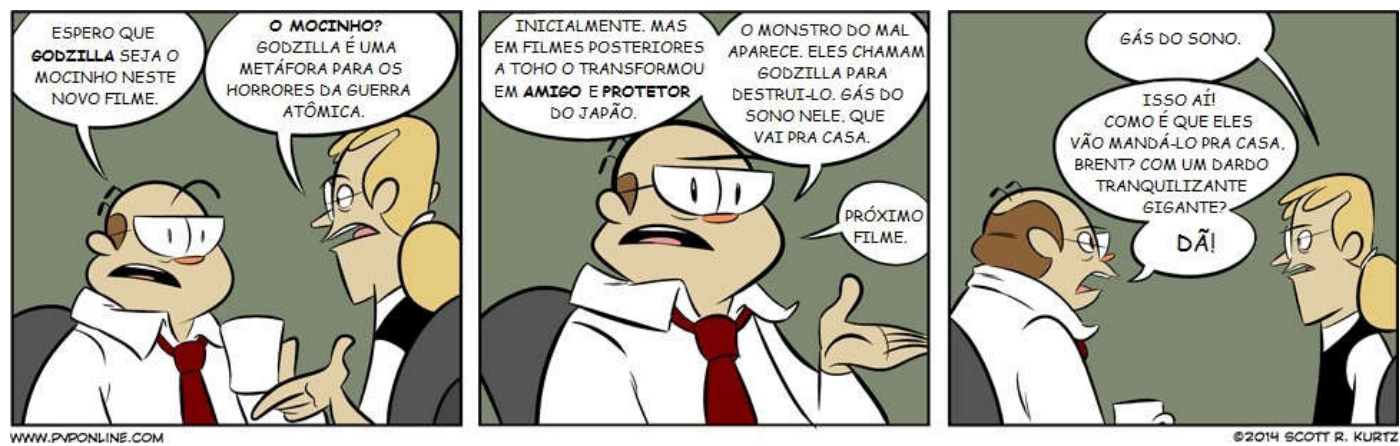

0 procedimento de equivalência foi selecionado para a tradução da onomatopeia "duh!” por seu equivalente em português “dã!”. A adaptação foi o procedimento usado para a versão em português do título da tira. 0 original utiliza uma expressão encontrada em xampus que se tornou uma metáfora para ações que são realizadas continuamente, indicando a ação dos antigos filmes japoneses de Godzilla: o monstro acorda, luta e dorme novamente até a próxima sequência. Minha tradução inicial envolveu o uso do monstro como uma arma (mesmo que seja do lado dos mocinhos), substituindo os procedimentos de higiene capilar por comandos dados a soldados ao acionar armas de fogo. Mantive o original "roar" ("rosnar") substituindo "preparar" e modifiquei os elementos restantes por "apontar" e "fogo", tendo em mente que Godzilla emite rajadas de fogo atômico pela boca, sendo este seu poder mais destrutivo. Contudo, desta forma a aliteração presente no original não 
NóBREGA, G. L. DA - Procedimentos de tradução em HQs digitais envolvendo cultura pop

seria mantida. Aceitei posteriormente a sugestão de usar Rugir, Repousar, Repetir, que mantém a idéia do que sempre acontece com Godzilla, com um resultado próximo da solução original.

\section{SHELLHEAD SHOCK}

\section{4/09/2015}
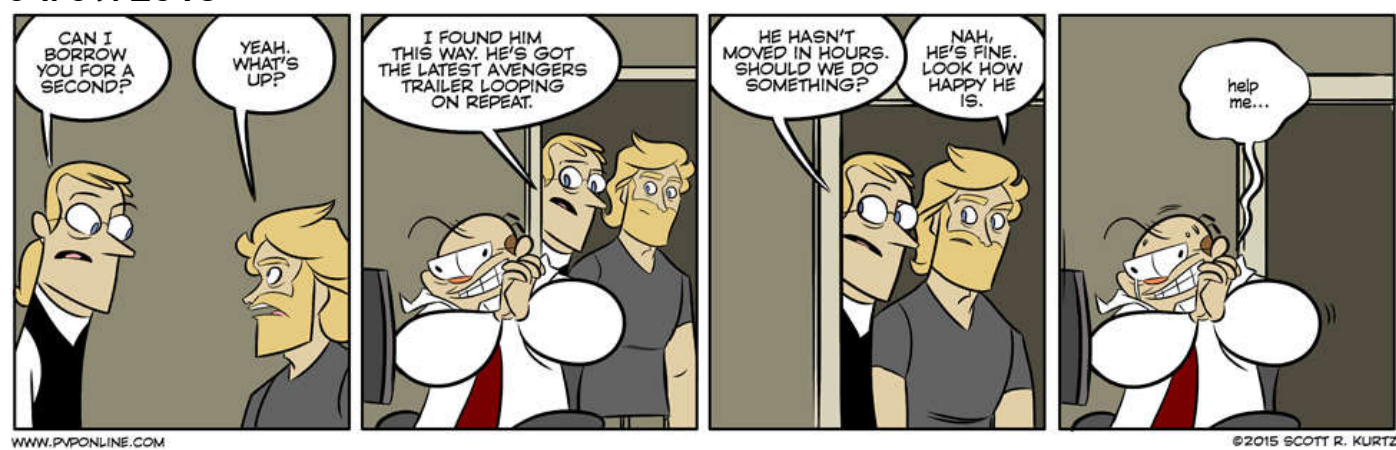

DISTÚRBIO (IRON) MENTAL

\section{9/04/2015}
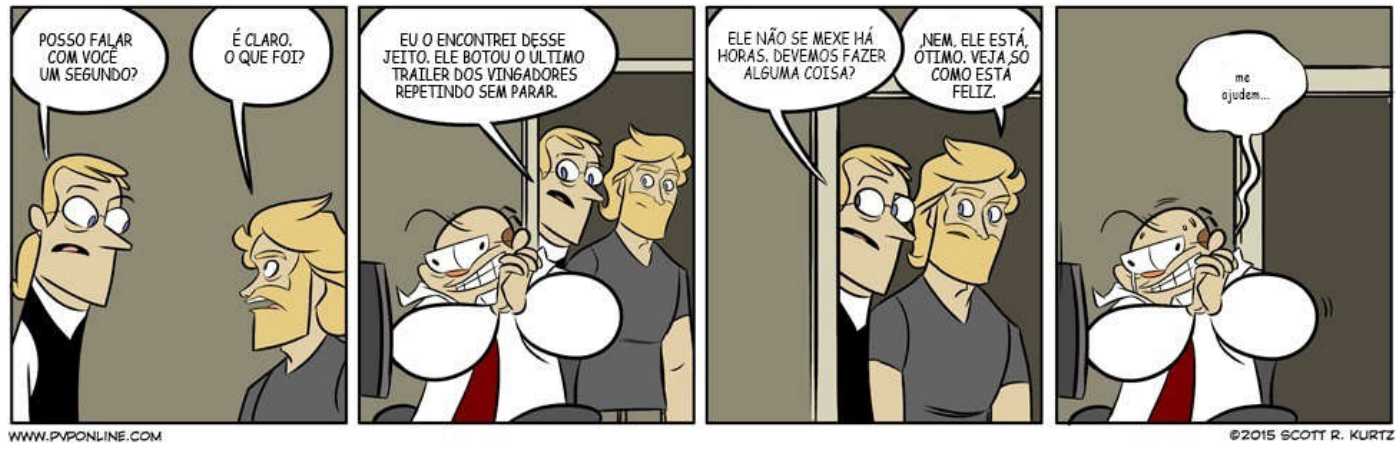

O procedimento utilizado na tradução da tira foi uma espécie de transferência com explicação. O Oxford Advanced Learner's Dictionary define o termo shell shock como um "distúrbio psicológico causado por exposição prolongada à guerra, especialmente sob bombardeio"2 (tradução minha). Expliquei o termo como distúrbio mental fazendo uma associação com o personagem Homem de Ferro (Iron Man), protagonista do filme Vingadores,

\footnotetext{
2 "psychological disturbance caused by prolonged exposure to active warfare, especially being under bombardment".
} 
NóBREGA, G. L. DA - Procedimentos de tradução em HQs digitais envolvendo cultura pop

cuja continuação tem o trailer como tema da tira, chegando à infame solução apresentada. Além disso, Shellhead é uma das nomenclaturas utilizadas pela Marvel Comics para se referir ao personagem interpretado por Robert Downey Jr. nos cinemas.

\section{AFICIONADUDES}

\section{$07 / 21 / 2014$}
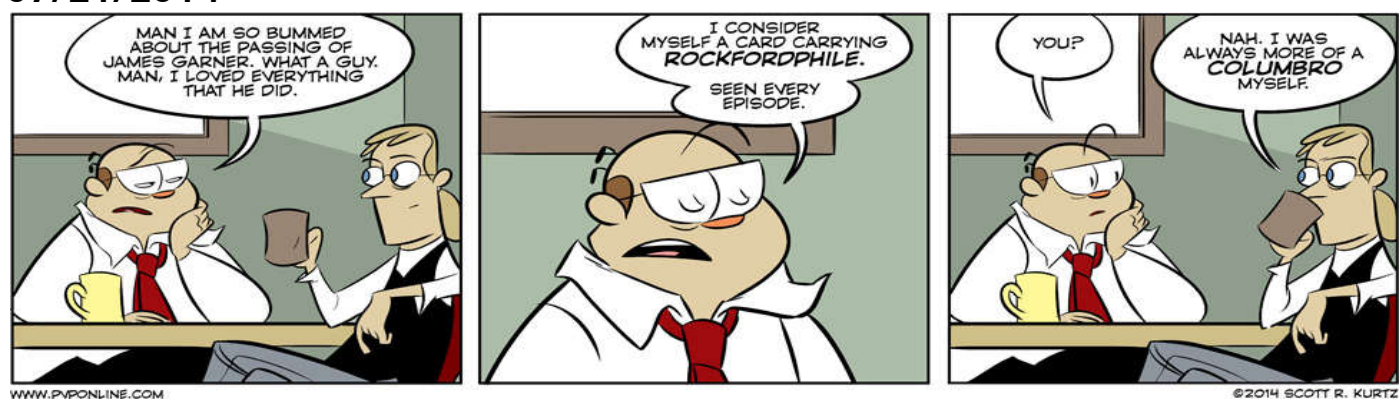

\section{VICIA-BROS}

\section{$07 / 21 / 2014$}
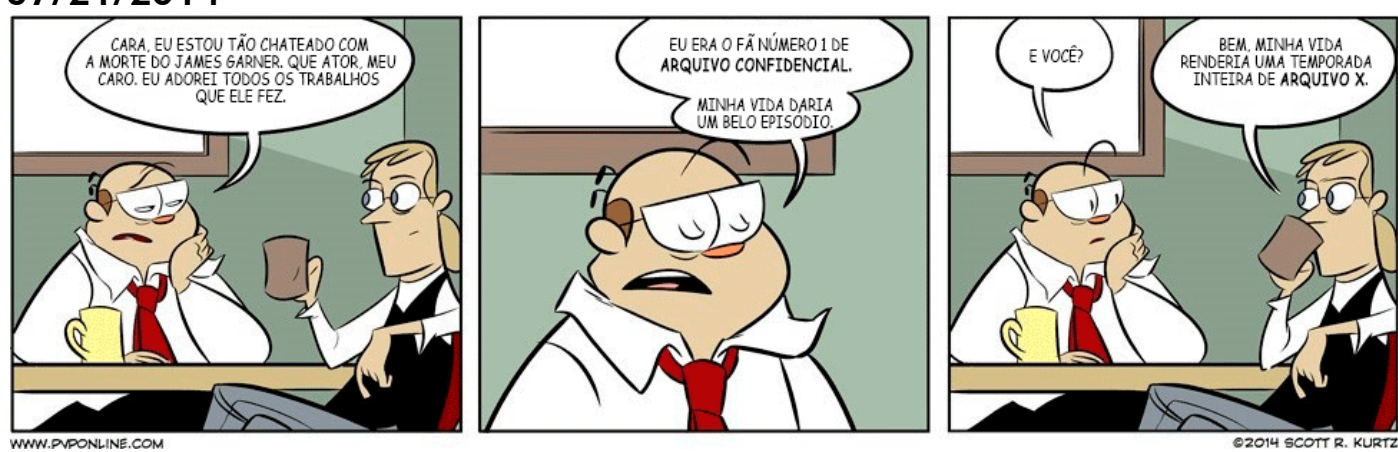

O procedimento de tradução é a adaptação, no trecho Columbro supracitado. Além de não haver um equivalente apropriado ao termo, manter o contexto de séries setentistas na língua da tradução alcançaria apenas leitores mais velhos. A intenção em relação a esta tira foi garantir o humor, alcançando um público, embora nerd/geek, mais amplo. Daí a resolução em focar no termo arquivo, presente tanto na tradução da série original quanto na daquele escolhido para substituir a referência de origem, Arquivo $X(X$ Files). A adaptação também ocorre na tradução do título da tira, onde fiz um 
NóBREGA, G. L. DA - Procedimentos de tradução em HQs digitais envolvendo cultura pop

amálgama entre as línguas inglesa e portuguesa para utilizar o termo bro (irmão, parceiro), o que não ocorreu no original.

\section{CODE WORDS}

01/08/14
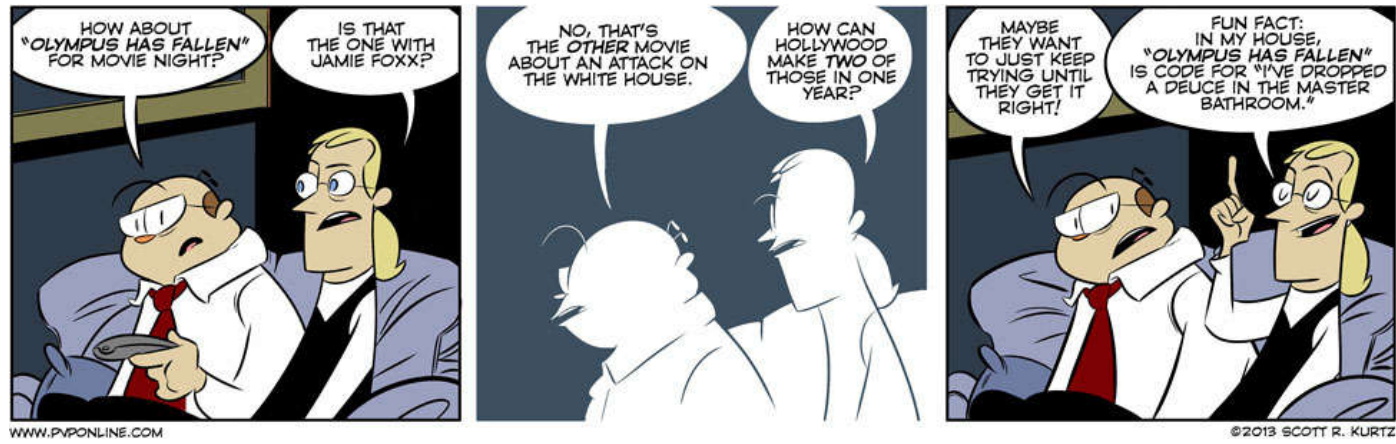

PALAVRAS-CÓDIGO

08/01/14
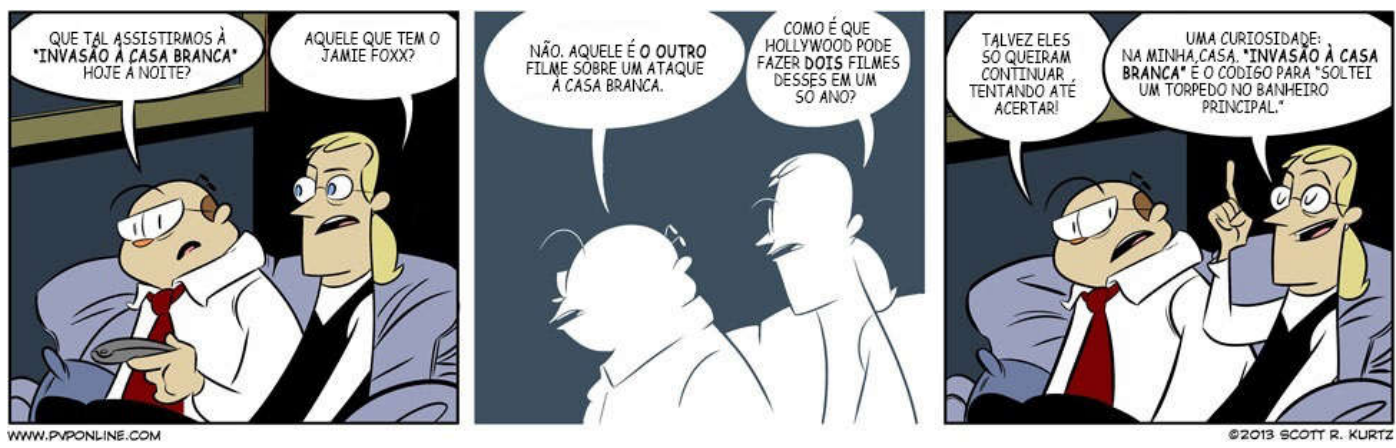

Emprega-se a adaptação como procedimento de tradução em boa parte das versões de títulos de filmes lançados em terras brasileiras, o qual é o caso do título apresentado na tira: "Invasão à Casa Branca". O curioso é o fato da tradução do título da película também se encaixar na metáfora encontrada no original: branco é a cor geralmente encontrada nos banheiros, além do assento sanitário apresentar majoritariamente tal coloração. A adaptação também ocorreu no trecho "I've dropped a deuce". A tradução literal poderia ter sido utilizada: "soltei o número 2". Porém, como o filme citado é um típico blockbuster americano, cheio de efeitos especiais, cenas de ação e explosões, a solução "soltei um torpedo" foi a metáfora escatológica 
NóBREGA, G. L. DA - Procedimentos de tradução em HQs digitais envolvendo cultura pop

escolhida. Para a tradução do título, o procedimento utilizado foi o decalque. A solução "senhas" chegou a ser cogitada, mas "palavras-código" tem, a meu ver, um ar mais cinematográfico, o que se encaixa melhor no contexto da tira.

NO WIN SCENARIO

$02 / 11 / 2013$

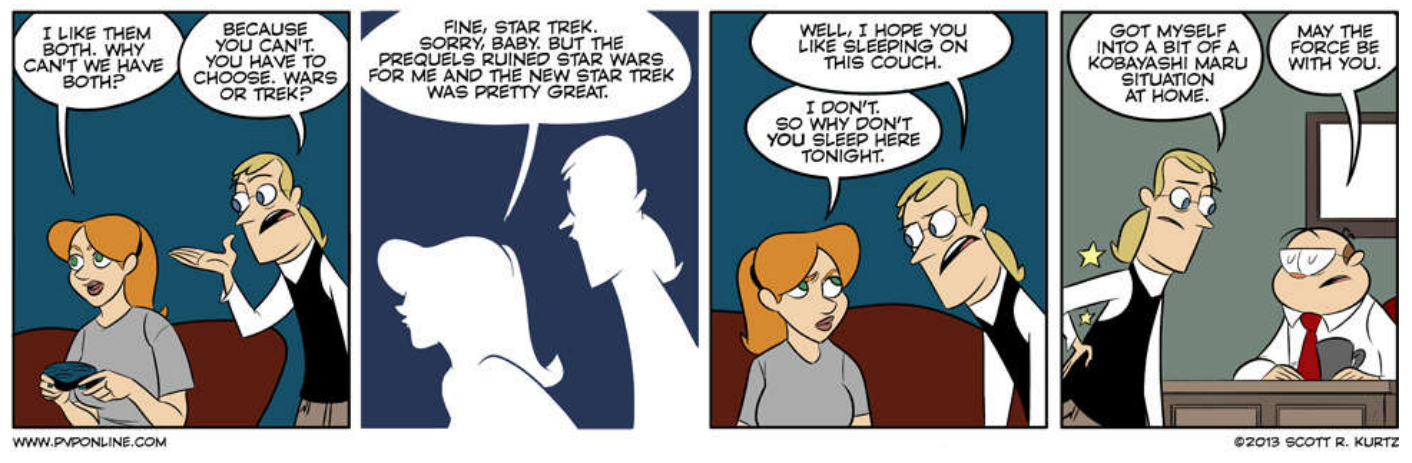

\section{A JORNADA DA GUERRA SEM VENCEDORES}

$02 / 11 / 2013$

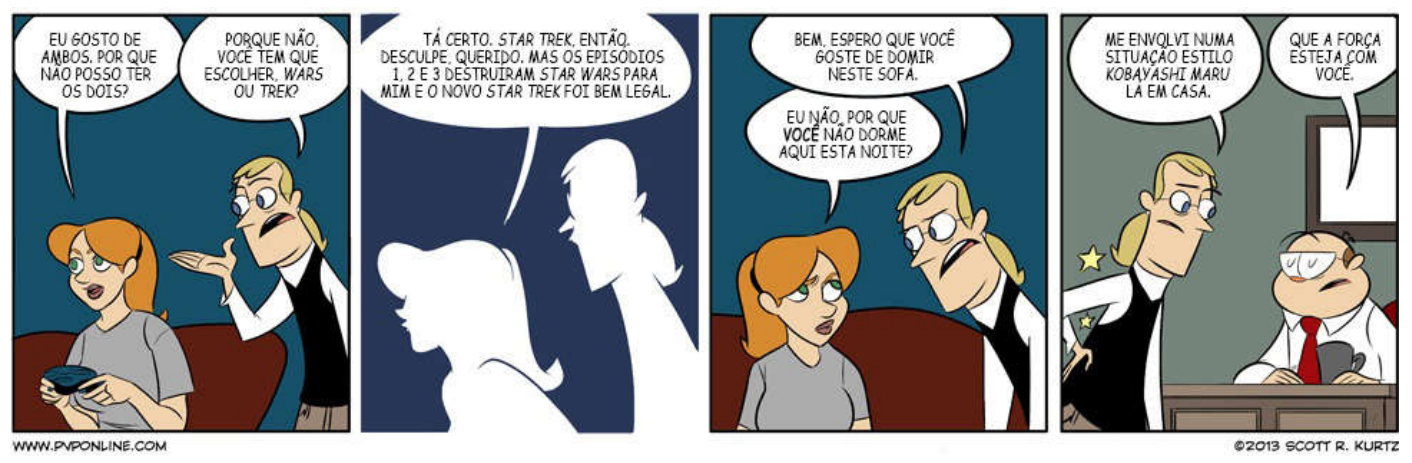

A manutenção do termo "Kobayashi maru" exemplifica o procedimento do estrangeirismo, no segundo balão do quarto requadro. Trata-se de um teste apresentado no já citado filme $A$ Ira de Khan e reapresentado no primeiro filme do novo Star Trek, e descreve uma situação onde não pode haver vencedores e é utilizado para testar o caráter dos cadetes da Frota Estelar, a organização que monitora a exploração espacial no universo do seriado. O capitão Kirk, comandante da Enterprise, conseguiu obter um 
NóBREGA, G. L. DA - Procedimentos de tradução em HQs digitais envolvendo cultura pop

resultado positivo no teste por meio de trapaça. A transposição é utilizada para a tradução já clássica de uma das frases mais conhecidas da saga Star Wars: "Que a força esteja com você". A adaptação foi utilizada para a versão nacional do título da tira, que se refere ao teste Kobayashi maru e a situação de Brent ao final da história. Mantive o foco da inexistência da vitória, citando também a tradução original de ambas as sagas.

\section{BRAND CONFUSION}

02/07/2013
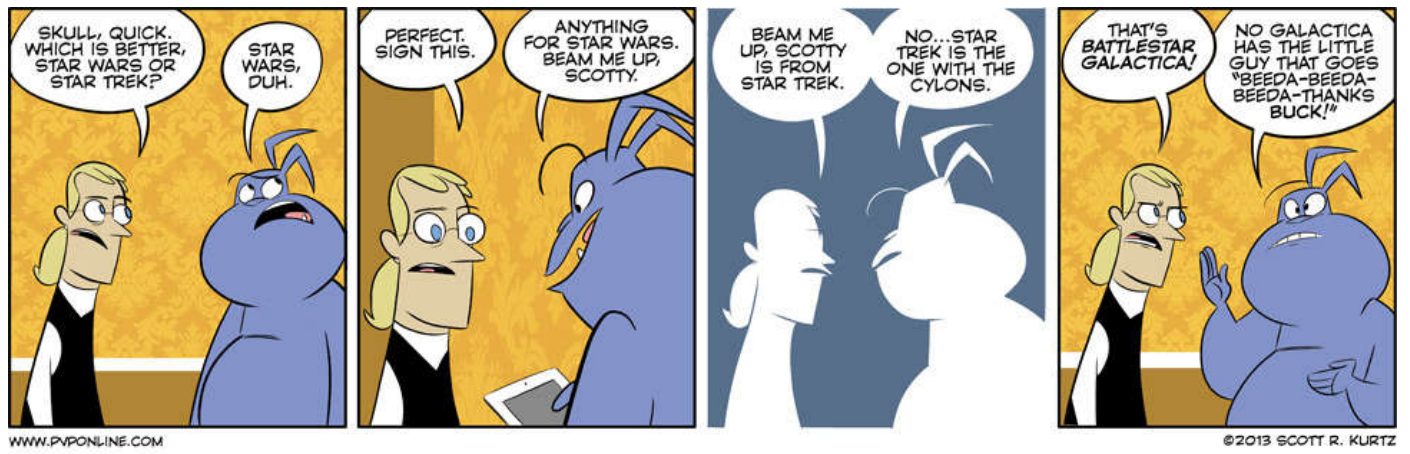

\section{DARTH VADER, DO PLANETA VULCANO}

\section{$07 / 02 / 2013$}
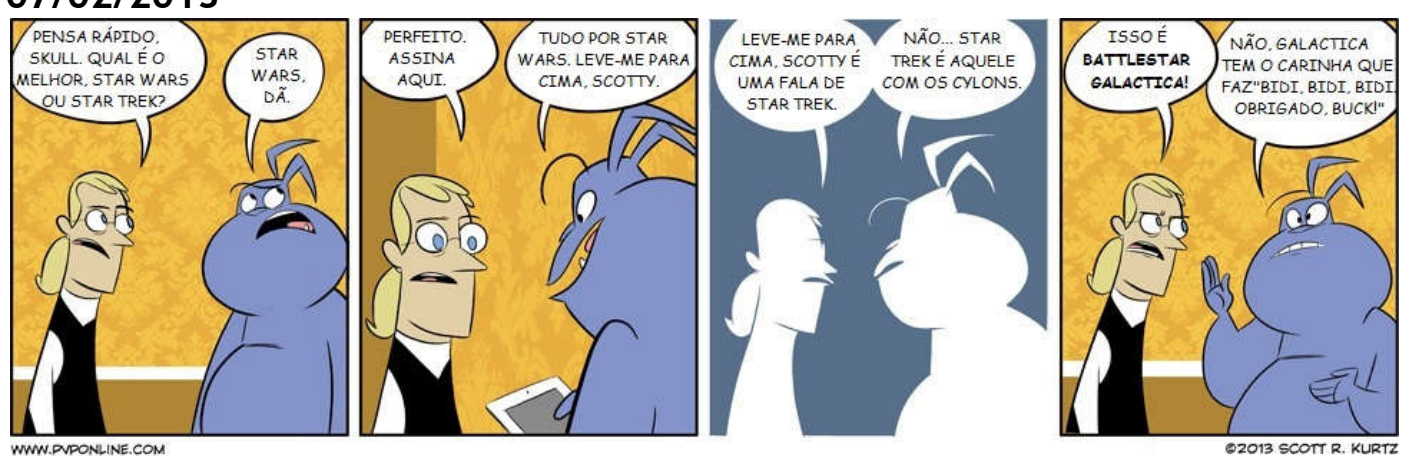

0 procedimento de estrangeirismo é utilizado para a manutenção dos termos "Battlestar Galactica" e "cylons" (seres cibernéticos que são parte da série), pois foi com esta forma que eles são reconhecidos na versão brasileira. Já a adaptação é usada na frase clássica da série Star Trek proferida pelo capitão Kirk toda vez que pedia para ser teleportado a bordo da nave Enterprise pelo engenheiro de bordo, Montgomery Scott (Scotty), encontrada 
NóBREGA, G. L. DA - Procedimentos de tradução em HQs digitais envolvendo cultura pop

no segundo balão do segundo requadro e no primeiro do terceiro requadro. A equivalência é novamente utilizada para a tradução do termo "duh". Em relação ao título a adaptação foi utilizada, fazendo uma citação/homenagem à cena no filme De Volta para o Futuro (1985) na qual Marty McFly, viajando no tempo, convence o pai a convidar a mãe para um baile, fingindo ser um alienígena chamado "Darth Vader, do planeta Vulcano", misturando o herói/vilão da série Star Wars com o planeta de origem do Sr. Spock.

\section{DARK WINGS DUMB TIDINGS}

04/03/2015
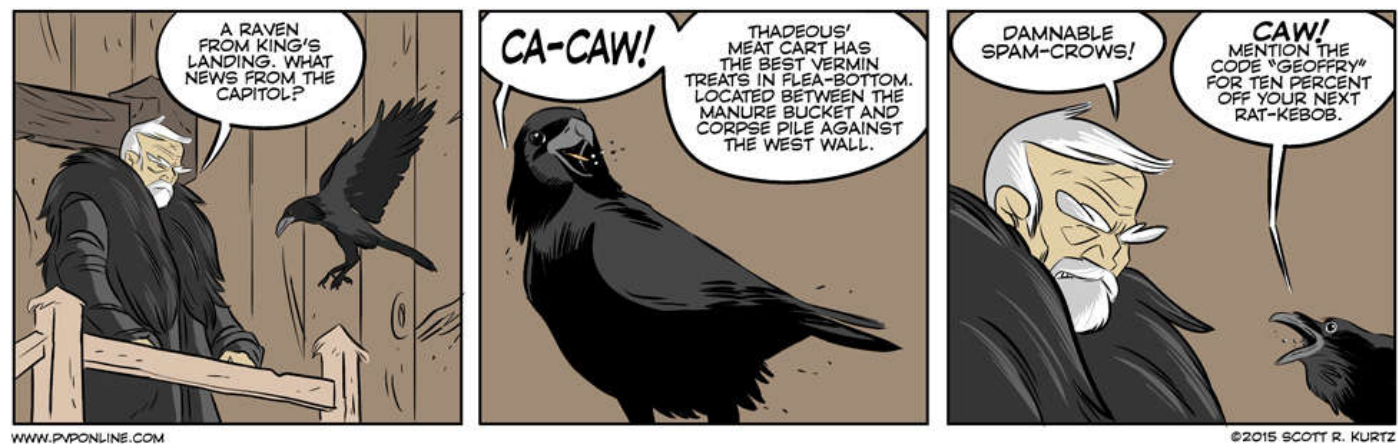

\section{ASAS NEGRAS, PALAVRAS BESTAS}

\section{3/04/2015}
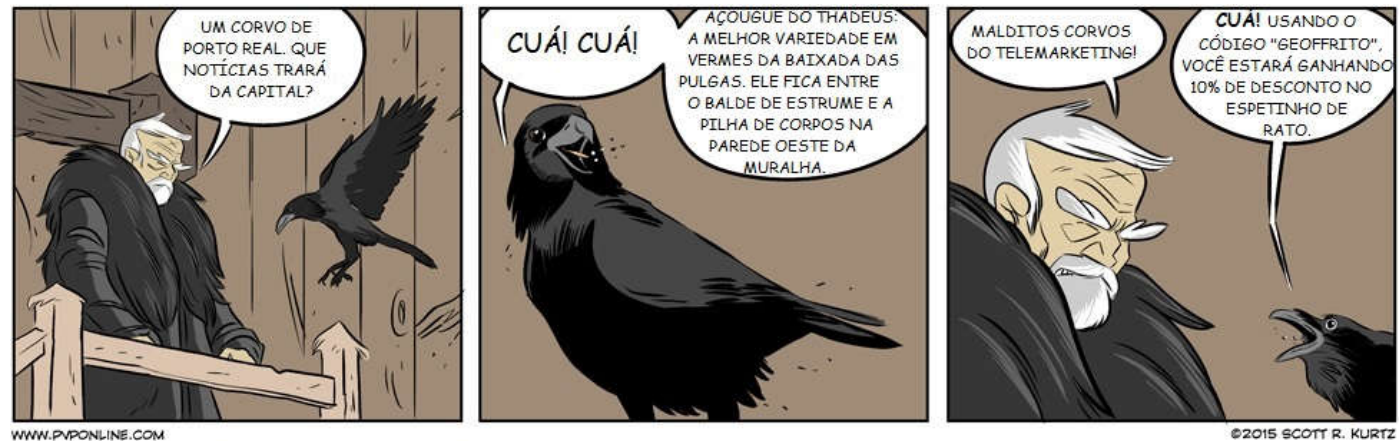

O procedimento de tradução literal foi utilizado para a versão brasileira, já utilizada nos livros e na série da HBO, dos locais fictícios criados por George R. R. Martin para a sua obra e mantida neste trabalho. É o que ocorre com King's Landing / Porto Real, Flea-Botttom / Baixada das Pulgase The Wall / A Muralha. A adaptação foi utilizada no trecho "spam-crows". A 
NóBREGA, G. L. DA - Procedimentos de tradução em HQs digitais envolvendo cultura pop

adaptação foi usada para a tradução do nome "Thadeous", apresentado na segunda tira do segundo requadro. Cogitei traduzi-lo para "Tadeu", mas assim ele perderia o ar medieval apresentado no contexto da tira, resolvendo manter Thadeus, então. Houve também a adaptação do termo "rat-kebob", que aparece no último balão da tira. Considerei "kebab de rato", mas posteriormente o modifiquei para "churrasquinho de rato". Porém, a menção ao uso de óleo na preparação do prato presente no trecho "geoffrito" me levou à solução "espetinho de rato". Apesar do termo spam ser conhecido no Brasil como os e-mails não solicitados, por vezes utilizados por empresas para alcançar um grande número de pessoas, achei que a referência ao telemarketing ampliaria o humor na realidade brasileira. Para tanto, ainda modifiquei o tempo verbal no segundo balão do terceiro requadro para emular o discurso geralmente apresentado pelos operadores de telemarketing: "você estará ganhando". A adaptação também foi utilizada para a tradução do título da tira, uma referência ao segundo episódio da terceira temporada do seriado Game of Thrones: Dark wings, dark words / Asas negras, palavras negras. Procurando manter tanto o termo "dumb" do original quanto à sonoridade de "negras", cheguei à versão apresentada: "Asas negras, palavras bestas".

\section{Considerações finais}

0 trabalho aqui realizado teve como objetivo analisar o processo de tradução de elementos da cultura pop presente nas webcomics selecionadas. Para tal, além da utilização dos conceitos teóricos apresentados por Vinay e Darbelnet e que foram revistos, atualizados e ampliados por Barbosa, houve a necessidade de exemplificar cada procedimento apresentado com um modelo encontrado dentro do universo pop. Desta maneira, além de apresentar as várias possibilidades que podem ser exploradas neste âmbito, é possível exemplificar a importância crescente que vêm acontecendo no estudo 
NóBREGA, G. L. DA - Procedimentos de tradução em HQs digitais envolvendo cultura pop

acadêmico das histórias em quadrinhos. Um exemplo é a realização de eventos como a Jornada Internacional de Histórias em Quadrinhos, evento bienal realizado na Universidade de São Paulo, que teve a sua $3^{\text {a }}$ edição realizada em 2015 com mais de 200 projetos acadêmicos apresentados tendo como tema a $9^{a}$ arte. Acredito também que, para que a tradução de um material que trata de elementos da cultura pop tenha um resultado efetivo e agrade leitores que fazem parte deste universo formado por nerds e geeks, o tradutor também deve pertencer a este meio, de modo que entenda os elementos linguísticos, culturais e imagéticos que obrigatoriamente serão parte de sua tarefa.

\section{Referências Bibliográficas}

AUBERT, F. H. A tradução literal: impossibilidade, inadequação ou meta? Ilha do Desterro, n. 17, Florianópolis (Universidade Federal de Santa Catarina), $1^{\circ}$ sem. 1987, pp.13-20.

BARbosa, H. G. Procedimentos técnicos da tradução: uma nova proposta. São Paulo: Pontes Editores, 1990.

KURTZ, S. R. Represent. Disponível em: www.pvponline.com/comic/represent. Acesso em: 31 jul. 2016.

KURTZ, S. R. Tales to astonish. Disponível em: www.pvponline.com/comic/talesto-astonish. Acesso em: 31 jul. 2016.

KURTZ, S. R. Mom Solo. Disponível em: www.pvponline.com/comic/mom-solo. Acesso em: 31 jul. 2016.

KURTZ, S. R. Roar, rinse, repeat. Disponível em: www.pvponline.com/comic/roar-rinse-repeat. Acesso em: 31 jul. 2016.

KURTZ, S. R. Shellhead shock. Disponível em: www.pvponline.com/comic/shellhead-shock. Acesso em: 31 jul. 2016.

KURTZ, S. R. Aficionadudes. Disponível em: www.pvponline.com/comic/aficionadudes. Acesso em: 31 jul. 2016.

KURTZ, S. R. Code words. Disponível em: www.pvponline.com/comic/codewords. Acesso em: 31 jul. 2016. 
NóBREGA, G. L. DA - Procedimentos de tradução em HQs digitais envolvendo cultura pop

KURTZ, S. R. No win scenario. Disponível em: www.pvponline.com/comic/nowin-scenario. Acesso em: 31 jul. 2016.

KURTZ, S. R. Brand confusion. Disponível em: www.pvponline.com/comic/brandconfusion. Acesso em: 31 jul. 2016.

KURTZ, S. R. Dark wings dumb tidings. Disponível em: www.pvponline.com/comic/dark-wings-dumb-tidings. Acesso em: 31 jul. 2016.

NeWmark, P. Approaches to translation. Oxford: Pergamon, 1981.

VÁZQUES-AYORA, G. Introducción a la traductologia: curso básico de traducción. Washington: Georgetown University, 1977.

VINAY, J; DaRbelnet, J. Comparative stylistics of French and English: a methodology for translation. Philadelphia: John Benjamins Publishing Company, 1958. 